Review Article

\title{
Comparison of the Efficacy and Safety of Different Doses of Linaclotide for Patients with Chronic Constipation: A Meta-Analysis and Bayesian Analysis
}

\author{
Jiao Yang and YanChang Lei 1 \\ Department of Gastroenterology, WenChang Road 8, Liuzhou People's Hospital, Liuzhou 545000, Guangxi, China \\ Correspondence should be addressed to YanChang Lei; leiyc2020@163.com
}

Received 9 March 2021; Revised 4 September 2021; Accepted 17 September 2021; Published 14 October 2021

Academic Editor: Valeria Sülsen

Copyright (C) 2021 Jiao Yang and YanChang Lei. This is an open access article distributed under the Creative Commons Attribution License, which permits unrestricted use, distribution, and reproduction in any medium, provided the original work is properly cited.

\begin{abstract}
Background. It is ambiguous whether a higher dose of linaclotide provides higher efficacy for chronic constipation (CC) patients. The meta-analysis aimed to assess the efficacy and safety of linaclotide doses ranging from $62.5 \mu \mathrm{g}$ to $600 \mu \mathrm{g}$ for CC patients. Methods. A comprehensive search was conducted, and STATA16 software was used for data analysis. Results. Seven studies with 4,107 patients were eligible. A significantly enhanced number of completely spontaneous bowel movement (CSBM) responders were found in the extremely low-dose group (OR: 2.94; 95\% CI: 1.98-4.34; $p<0.001$ ), the low-dose group (OR: 3.24; 95\% CI: $2.44-4.31 ; p<0.001$ ), the medium-dose group (OR: 3.08; 95\% CI: $1.46-6.50 ; p=0.003$ ), and high-dose group (OR: 4.79; 95\% CI: $3.04-7.54 ; p<0.001)$. Bayesian analysis showed the high-dose group obtained the maximum CSBM responder rate (OR: $4.94 ; 95 \%$ credible interval (CrI): 3.22-7.79; probability rank = 0.87) indirectly compared with extremely low-dose, low-dose, and mediumdose groups. However, no significant difference presented in the CSBM responder rate by pairwise comparisons of the different dose groups. Additionally, no more any adverse events occurred in the higher linaclotide dose group (RR: 0.91; 95\% CrI: 0.60-1.38) indirectly compared with other dose groups. Conclusions. High dose of linaclotide could be more effective and safer for CC patients, which need more trials to confirm in the future.
\end{abstract}

\section{Introduction}

Chronic constipation (CC) may be primary (idiopathic or functional) or secondary to several disorders or medications. CC is characterized by various bowel symptoms, including infrequent bowel movement, hard stools, excessive straining to defecate, a sense of anorectal blockage, anal digitation, and a sense of incomplete evacuation. The most widely used diagnostic criteria of CC are the Rome criteria, and the latest is Rome IV, created in 2016 [1], which distinguishes functional constipation from irritable bowel syndrome with constipation (IBS-C).

CC negatively affects the quality of life, comparable with chronic diseases, such as chronic obstructive pulmonary disease, diabetes, and depression $[2,3]$. In contrast, poor quality of life can aggravate CC symptoms. The estimated incidence of CC ranges from $11 \%$ to $20 \%$ [4-6].
Approximately one in five people presented with CC symptoms will seek medical help [7]. There has been a steady and significant increase in the proportion of ambulatory care related to this disorder [8], and it poses a heavy economic burden for healthcare systems $[9,10]$. Thus far, the risk factors for CC identified are advanced age, female, low socioeconomic status, low parental education rates, decreased physical activity, certain medications, stressful life events, physical and sexual abuse, and depression $[11,12]$.

There are many choices available for the treatment of CC, including changes in defecation habits, increase in fiber intake, and several drugs, such as laxatives and systemically active agents. However, up to $50 \%$ of patients report that they are not completely satisfied with current treatment due to inefficient relief from constipation, the side effects of drugs (e.g., bloating and abdominal pain), the lack of predictability of laxative action, and partial improvement of the quality of life [13]. 
Linaclotide, a peptide homolog of Escherichia coli ST toxin, interacts with the guanylate cyclase C (GC-C) located in the enterocyte apical membrane. Activation of the GC-C receptor results in cyclic GMP production that induces the secretion of fluids and electrolytes into the lumen, accelerates colonic transit, and relieves constipation [14]. Many studies have confirmed that linaclotide is superior to the placebo and safe for use in a clinical setting [15-17]. Nevertheless, the optimal dose of linaclotide is still not confirmed. Linaclotide at doses of $145 \mu \mathrm{g}$ and $290 \mu \mathrm{g}$ has demonstrated an adequate level of safety and efficacy in two large RCTs conducted on CC patients [18]. However, only the $145 \mu \mathrm{g}$ dose was approved for CC treatment in adults. A linaclotide dosage of $290 \mu \mathrm{g}$ once per day is considered safe and effective for IBC-C patients in the USA [19-21]. However, a study from Japan showed that $500 \mu \mathrm{g}$ linaclotide resulted in a higher monthly responder rate in a global assessment of relief from IBS symptoms, responder rate of completely spontaneous bowel movement (CSBM), and responder rate of abdominal pain or discomfort relief than those with placebo [22], which indicates that a linaclotide dose of $500 \mu \mathrm{g}$ may be appropriate for IBS-C patients. Similarly, there is ambiguity on whether a high dose of linaclotide provides higher efficacy for CC patients. Therefore, in this study, we aimed to assess the effect and safety of different doses of linaclotide for the treatment of CC.

\section{Materials and Methods}

This meta-analysis was conducted following PRISMA guidelines. A comprehensive search of the PubMed, the Cochrane Library, and the Embase was performed using the search terms: linaclotide and chronic constipation.

\subsection{Inclusion Criteria}

(1) Randomized controlled trial (RCT)

(2) Participants had to be diagnosed with CC

(3) Participants had to be treated using linaclotide

(4) The language had to be English

\subsection{Exclusion Criteria}

(1) Participants were diagnosed with IBS-C

(2) Incomplete data

(3) The publication was a letter, comment, editorial, or case report

2.3. Study Selection and Data Extraction. The detailed selection process is summarized in the PRISMA flow diagram. Two authors (Jiao Yang and YanChang Lei) independently identified the full-text manuscripts of these studies based on the inclusion criteria and conducted data extraction for the primary and secondary endpoints. Conflicts were resolved by discussion. The primary endpoint was the number of CSBM responders. The secondary endpoints were the number of spontaneous bowel movement (SBM) responders, the number of responders of the global assessment of relief, the number of responders of abnormal bowel habits improvement, and the number of responders of abdominal symptoms relief. The definition of a CSBM/SBM responder was a patient who had reported at least 3 CSBMs/SBMs and an increase of 1 or more CSBMs/SBMs from the baseline at each evaluation point. Responders for global assessment of relief of CC symptoms, abnormal bowel habits improvement, and abdominal symptoms relief were defined as patients with a score of 1 or 2 at each evaluation point.

Moreover, the baseline characteristics, such as country, number of centers, diagnostic criteria for CC, the total number of patients, the proportion of female patients, dose of linaclotide, duration, and outcomes, of the randomized controlled trials were recorded. The extremely low-dose group of patients received $62.5 \mu \mathrm{g}, 72 \mu \mathrm{g}$, or $75 \mu \mathrm{g}$ of linaclotide. The low-dose group of patients received $145 \mu \mathrm{g}$ or $150 \mu \mathrm{g}$ of linaclotide. The medium-dose group of patients received $290 \mu \mathrm{g}$ or $300 \mu \mathrm{g}$, and the high-dose group received $500 \mu \mathrm{g}$ or $600 \mu \mathrm{g}$ of linaclotide.

2.4. Statistical Analysis. STATA 16 software was used to perform the statistical analyses. All outcomes were dichotomous variables. The risk ratio (RR), odds ratio (OR), and 95\% confidence intervals (CI) were calculated. Additionally, heterogeneity was analyzed using $I^{2}$ or $p$ statistics. If $I^{2}>50 \%$ or $p<0.1$, indicating heterogeneity, the random-effects model was used. Otherwise, the fixed-effects model was applied. Publication bias was assessed by funnel plots and Begg's test. The quality of the eligible studies was evaluated by Cochrane's risk of bias tool (RevMan 5.3 software) including random sequence generation, allocation concealment, blinding of participants and personnel, blinding of the outcomes assessment, incomplete outcome data, selective reporting, and other biases. In addition, $R$ software (3.6.3) with GEMTC and RJAGS packages was utilized to perform Bayesian analysis to rank the optimal dose of linaclotide [23, 24]. The surface under the cumulative ranking (SUCRA) ranging between $0 \%$ and $100 \%$ was used to rank the probability of the optima dose of linaclotide [23]. 95\% credible interval (CrI) was derived from the $2.5^{\text {th }}$ and $97.5 \%^{\text {th }}$ percentiles.

2.5. Level of Evidence. The Grading of Recommendation Assessment, Development, and Evaluation approach (GRADE) was applied to assess the quality of the evidence associated with the meta-analysis primary outcomes results.

\section{Results}

3.1. Study Characteristics. Seven studies [18, 25-30] and eight RCTs conducted on 4,107 patients were eligible to be included in the study. Most eligible RCTs were conducted at multiple centers. The CC diagnostic criteria used was Rome II or Rome III. Moreover, the majority of patients were female. The duration of treatment ranged from 2 weeks to 12 weeks and is given in Table 1. The detailed search process is shown in Figure 1. 
TABLE 1: Baseline characteristics of the eligible studies.

\begin{tabular}{|c|c|c|c|c|c|c|c|c|}
\hline Study & Country & Centers & $\begin{array}{l}\text { Diagnostic } \\
\text { criteria for CC }\end{array}$ & $\begin{array}{c}\text { Total } \\
\text { number }\end{array}$ & $\begin{array}{l}\text { Female } \\
\quad(\%)\end{array}$ & $\begin{array}{c}\text { Dose of } \\
\text { linaclotide } \\
(\mu \mathrm{g})\end{array}$ & $\begin{array}{l}\text { Treatment } \\
\text { time }\end{array}$ & Outcomes \\
\hline $\begin{array}{l}\text { Fukudo1, } \\
2018\end{array}$ & Japan & NA & Rome III & 382 & 83.25 & $\begin{array}{c}62.5,125 \\
250,500\end{array}$ & $2 \mathrm{w}$ & $\begin{array}{l}\text { CSBM responder; SBM responder; } \\
\text { global assessment of relief; abnormal } \\
\text { bowel habits improvement; } \\
\text { abdominal symptoms relief }\end{array}$ \\
\hline Lembo, 2010 & USA & 57 & Rome II & 310 & 91.86 & $\begin{array}{c}75,150,300 \\
600\end{array}$ & $4 \mathrm{w}$ & $\begin{array}{l}\text { CSBM responder; SBM responder; } \\
\text { abnormal bowel habits } \\
\text { improvement }\end{array}$ \\
\hline $\begin{array}{l}\text { Fukudo2, } \\
2018\end{array}$ & Japan & 39 & Rome III & 181 & 82.32 & 500 & $4 \mathrm{w}$ & $\begin{array}{l}\text { CSBM responder; SBM responder; } \\
\text { global assessment of relief; abnormal } \\
\text { bowel habits improvement; } \\
\text { abdominal symptoms relief }\end{array}$ \\
\hline Lacy, 2015 & $\begin{array}{c}\text { USA } \\
\text { Canada }\end{array}$ & 141 & Rome II & 483 & 91.5 & 145,290 & $12 \mathrm{w}$ & $\begin{array}{l}\text { CSBM responder; global assessment } \\
\text { of relief; abnormal bowel habits } \\
\text { improvement; abdominal symptoms } \\
\text { relief }\end{array}$ \\
\hline $\begin{array}{l}\text { Schoenfeld, } \\
2017\end{array}$ & USA & 105 & Rome III & 1223 & 77 & 72,145 & $12 \mathrm{w}$ & $\begin{array}{c}\text { CSBM responder; global assessment } \\
\text { of relief }\end{array}$ \\
\hline Lembo, 2011 & $\begin{array}{c}\text { USA } \\
\text { Canada }\end{array}$ & 212 & Rome II & 1276 & 88.64 & 145,290 & $12 \mathrm{w}$ & $\begin{array}{l}\text { CSBM responder; global assessment } \\
\text { of relief; abdominal symptoms relief }\end{array}$ \\
\hline $\begin{array}{l}\text { Brenner, } \\
2020\end{array}$ & USA & 71 & Rome III & 252 & 59.9 & 145,290 & $8 w$ & SBM responder \\
\hline
\end{tabular}

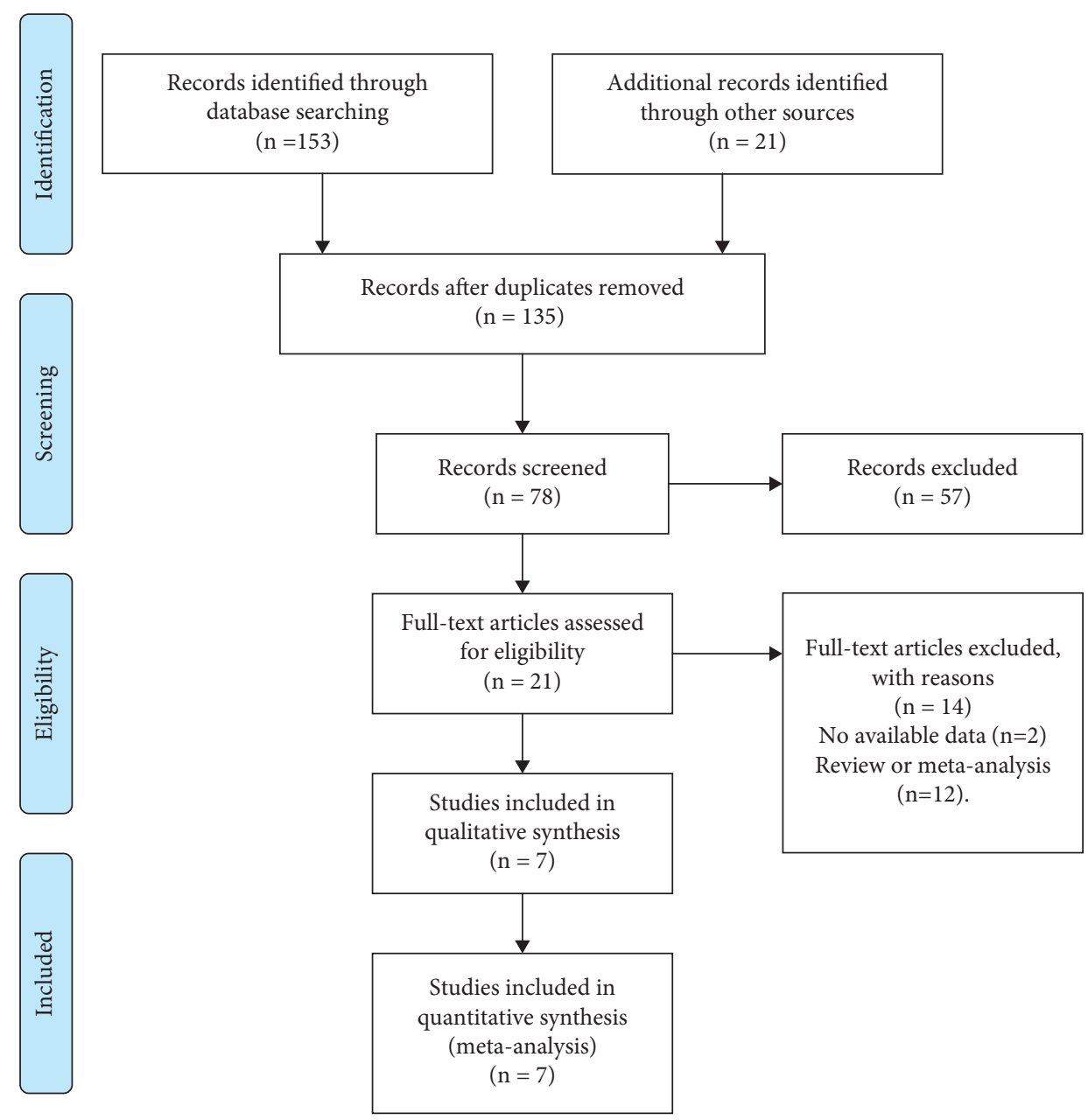

FIGURE 1: Flow diagram of the literature review process. 
3.2. The Quality of the RCTs. The quality of all eligible studies was evaluated using the risk of bias tool of the Cochrane collaboration network. Random sequence generation, allocation concealment, blinding of participants and personnel, blinding of outcome assessment, and incomplete outcome data were found to be low risk. Selective reporting and other biases showed an unclear risk of bias, as shown in Figure 2. In total, the quality of these studies was found to be optimal.

\subsection{Outcomes}

3.3.1. CSBM Responders. Seven RCTs reported on the number of CSBM responders in the linaclotide group and placebo group. The fixed-effects model was used because no significant heterogeneity was found $\left(I^{2}=27.9 \%\right.$ or $p=0.216)$. The number of CSBM responders was significantly higher in the linaclotide group than the placebo group (OR: 3.59; 95\% CI: 2.82-4.57; $p<0.001$ ). Then, a stratified analysis was conducted between patients administered different doses of linaclotide and the placebo. The number of CSBM responders in the extremely low-dose group (OR: 2.94; 95\% CI: $1.98-4.34 ; p<0.001$ ), low-dose group (OR: 3.24; 95\% CI: 2.44-4.31; $p<0.001$ ), medium-dose group (OR: 3.08; 95\% CI: 1.46-6.50; p: 0.003), and high-dose group (OR: 4.79 ; 95\% CI: 3.04-7.54; $p<0.001$ ) was higher than that of the placebo, as shown in Figure 3.

3.3.2. SBM Responders. Four studies conducted on 1,123 patients reported on the number of SBM responders. $I^{2}=45.6 \%$ or $p=0.138$ indicated that the level of heterogeneity was not significant, and the fixed-effects model was applied. Compared with the placebo group, the number of SBM responders increased significantly in the linaclotide group (OR: $2.41 ; 95 \% \mathrm{CI}: 1.82-3.20 ; p<0.001$ ), as given in Table 2 .

The low-dose group and the medium-dose group were further analyzed. We applied the fixed-effects model because the level of heterogeneity was not significant and found that the efficacy was comparable with the number of SBM responders between the low-dose group and medium-dose group (OR: $0.75 ; 95 \% \mathrm{CI}: 0.50-1.12 ; p=0.156$ ), as given in Table 2.

3.3.3. Responders of the Global Assessment of Relief. A total of 3,837 patients reported the incidence of responders in the global assessment of relief. More patients reported as responders in the global assessment of relief in the linaclotide group than those in the placebo group (OR: 3.45; 95\% CI: 2.28-5.22; $p<0.001$ ), as given in Table 2. However, the number of responders in the global assessment of relief presented among the low-dose group vs. medium-dose group (OR: $0.95 ; 95 \%$ CI: $0.77-1.17 ; p=0.626$ ) was not significant, as given in Table 2 .

3.3.4. Responder of Abnormal Bowel Habits Improvement. Three trials reported on responders of abnormal bowel habits improvement as an outcome. More patients in the linaclotide group presented abnormal bowel habits improvement than those in the placebo group (OR: 3.73; 95\% CI: 2.59-5.36; $p<0.001$ ), as given in Table 2. There was no significant improvement in abnormal bowel habits presented between the low-dose group and medium-dose group (OR: 1.29; 95\% CI: 0.85-1.97; $p=0.23$ ), as given in Table 2.

3.3.5. Responders of Abdominal Symptoms Relief. Five trials conducted on 2,307 patients reported on the number of responders of abdominal symptoms relief. More patients in the linaclotide group reported as responders of abdominal symptoms relief than those in the placebo group (OR: 2.76; 95\% CI: 2.28-3.34; $p<0.001$ ), as given in Table 2. However, compared to those in the medium-dose group, patients in the low-dose group presented no significant enhancement in abdominal symptoms relief (OR: 0.91; 95\% CI: 0.61-1.36; $p<0.001$ ), as given in Table 2 .

3.3.6. Adverse Effects (AEs). Patients in the linaclotide group presented with more any AEs (RR: 1.23; 95\% CI: 1.13-1.33; $p<0.001$ ), gastrointestinal disorders (RR: 2.03; 95\% CI: 1.34-3.09; $p=0.001$ ), diarrhea (RR: 3.10; 95\% CI: 2.43-3.95; $p<0.001$ ), and infections (RR: 1.45 ; 95\% CI: 1.15-1.83; $p=0.002$ ) than those in the placebo group, as given in Table 2.

3.4. Bayesian Analysis for Optimal Dose of Linaclotide. Due to no significant inconsistency, the consistency model was used to analyze the results of the CSBM responder rate and any AEs. Compared to placebo, patients with different doses of linaclotide reported more responders of CSBM. Patients with high dose of linaclotide presented the maximum rate of CSBM responders (OR: 4.94; 95\% CrI: 3.22-7.79; probability rank $=0.87$ ) indirectly compared with other dose groups, as shown in Figure 4(a). More any AEs occurred in the extremely low-dose group (RR: 1.34; 95\% CrI: 1.05-1.96), low-dose group (RR: 1.26; 95\% CrI: 1.06-1.62), and mediumdose group (RR: 1.23 ; 95\% CrI: $1.03-1.67$ ), but in the highdose group (RR: 0.91 ; 95\% CrI: 0.60-1.38) than those with placebo. By indirect comparison with other dose groups, extremely low dose of linaclotide obtained the highest incidence of any AE with probability rank $=0.59$ and high dose of linaclotide ranked the fourth (probability rank=0.01), as shown in Figure 4(b). But by pairwise comparison of the different dose groups, no statistical significance demonstrated the outcomes of the rate of CSBM responders and the incidence of any AE, as given in Table 3 .

3.5. Publication Bias. A funnel plot and Begg's test were used to evaluate the publication bias, and no significant publication bias was presented for these outcomes (CSBM responders, SBM responders, and any adverse events), as shown in Figure 5.

3.6. Level of Evidence. The eligible studies were RCTs, and the level of evidence using GRADE instruments was high. In 


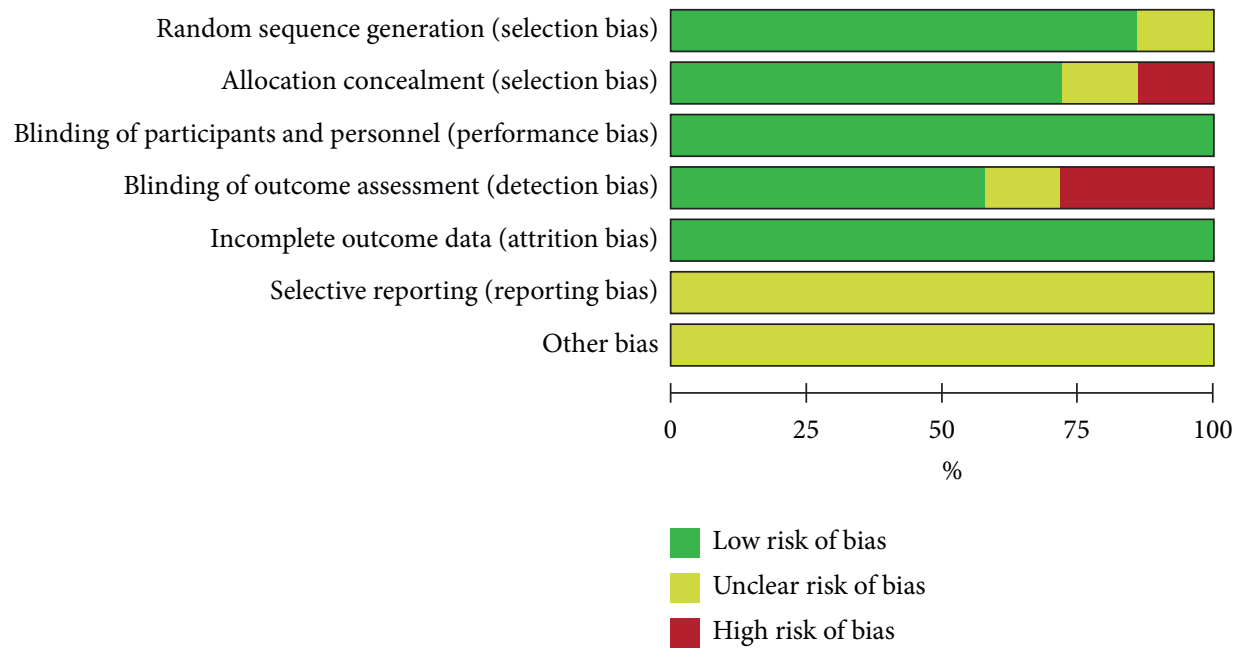

(a)

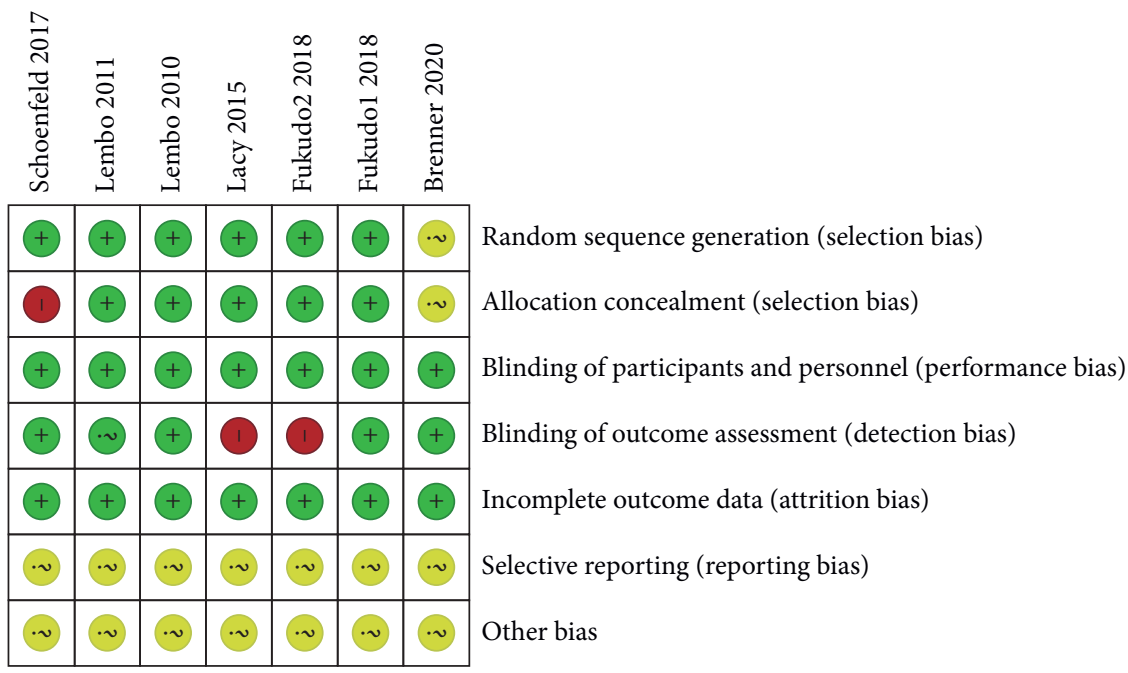

(b)

Figure 2: The quality of the RCTs. (a) Risk of bias graph of the eligible studies. (b) Risk of bias summary of the eligible studies.

total, these studies provided a moderate to high level of evidence of the CSBM responder rate in Supplementary Materials (available here).

\section{Discussion}

The effects of different doses of linaclotide on CC have been assessed, resulting in confusing outcomes for clinicians. Therefore, we conducted a meta-analysis to evaluate whether a high dose of linaclotide would present more benefits for patients with CC. Up to date, this is the first meta-analysis to assess the efficacy of different doses of linaclotide. In this study, we found that the efficacy of each linaclotide dose was better than that of the placebo and was tolerable for patients with CC. Furthermore, the high dose of linaclotide was more efficacious and resulted in no more adverse events in patients with CC by indirect comparison with other dose of linaclotide.

Linaclotide, which targets GC-C receptors on the lumen of the intestinal epithelium, has been approved by the US Food and Drug Administration (FDA) for the treatment of chronic constipation (145 $\mu$ g daily) and IBS-C (290 $\mu$ g daily) in 2012 [31]. In 2017, a $72 \mu \mathrm{g}$ dose of linaclotide was approved by the FDA for treating chronic idiopathic constipation [31]. An RCT conducted at 14 clinical study centers in the United States reported that higher doses of linaclotide was associated with increased colonic transit and an increase in bowel motion frequency and consistency but reduced the straining scores of patients [32], indicating that a high dose of linaclotide may improve symptoms of patients with CC. However, a study conducted on 420 patients assessed the efficacy of linaclotide at daily doses of $75,150,300$, or $600 \mu \mathrm{g}$ or a placebo and found no dose-dependent increase in CSBMs, SBMs, stool consistency, and straining in patients with IBS-C [33]. In our study, we found that linaclotide significantly increased the CSBM responder rate and SBM responder rate. By Bayesian analysis, it seemed the rate of CSBM responders was on the increase for higher dose of linaclotide (OR for extremely low-dose, low-dose, mediumdose, and high-dose was 3.2, 3.28, 3.66, and 4.94, 


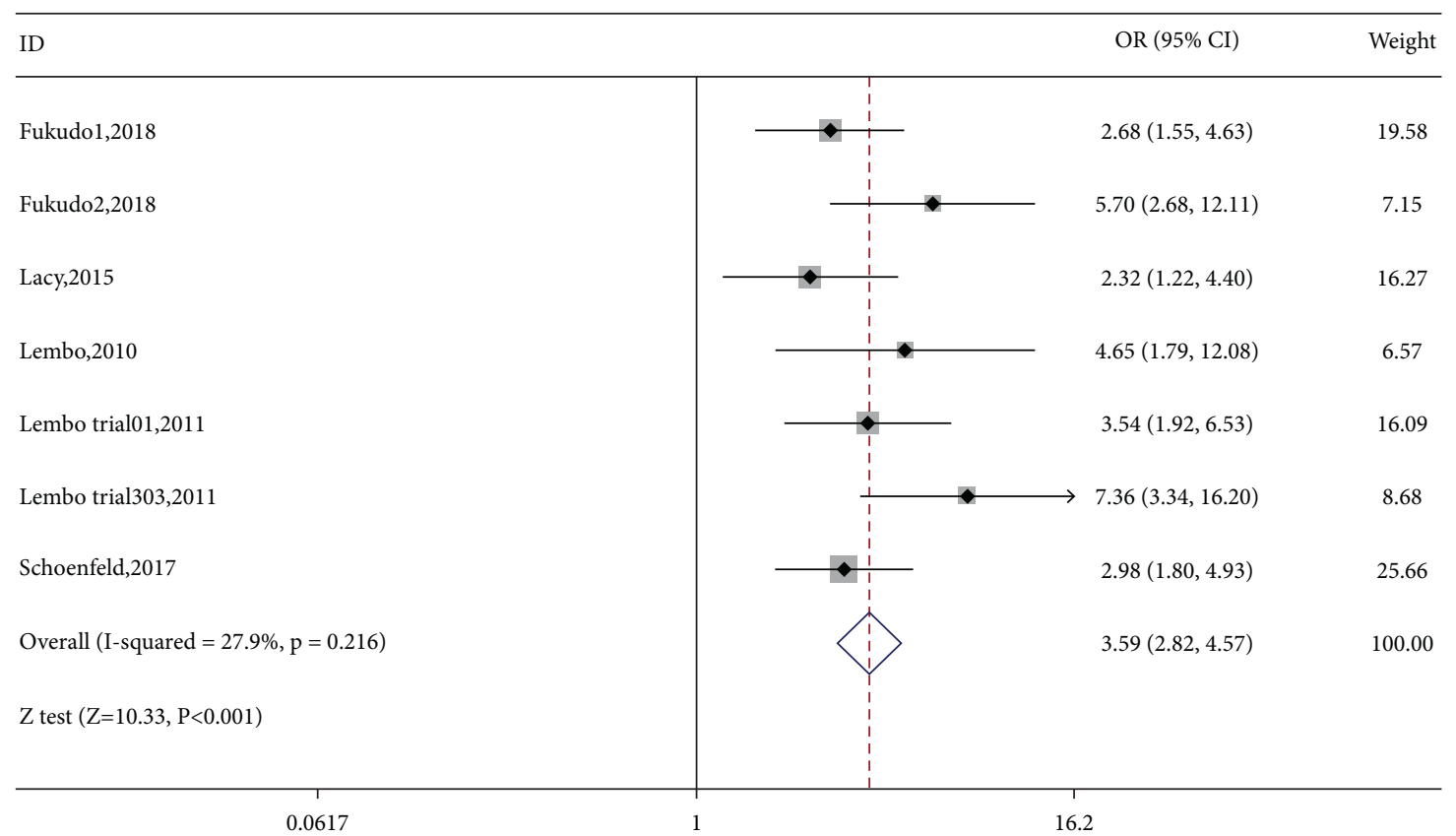

(a)

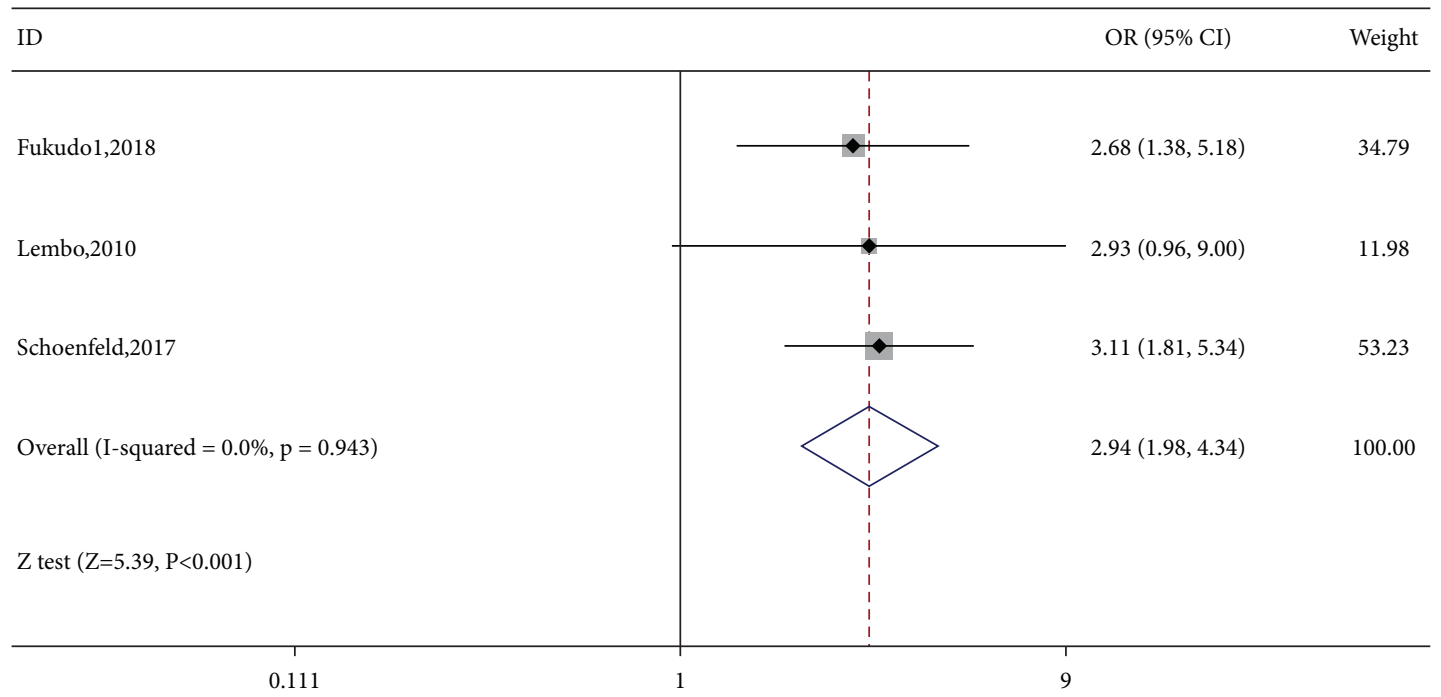

(b)

Figure 3: Continued. 


\begin{tabular}{|c|c|c|}
\hline ID & OR $(95 \% \mathrm{CI})$ & Weight \\
\hline Fukudo1,2018 & $2.31(1.16,4.56)$ & 18.76 \\
\hline Lacy,2015 & $2.26(1.11,4.62)$ & 17.90 \\
\hline Lembo,2010 & $4.68(1.58,13.86)$ & 5.67 \\
\hline Lembo trial01,2011 & $2.95(1.51,5.77)$ & 18.81 \\
\hline Lembo trial303,2011 & $7.76(3.42,17.64)$ & 9.72 \\
\hline Schoenfeld,2017 & $2.85(1.65,4.92)$ & 29.14 \\
\hline Overall $(\mathrm{I}$-squared $=28.7 \%, \mathrm{p}=0.220)$ & $3.24(2.44,4.31)$ & 100.00 \\
\hline $\mathrm{Z}$ test $(\mathrm{Z}=8.11, \mathrm{P}<0.001)$ & & \\
\hline
\end{tabular}

(c)

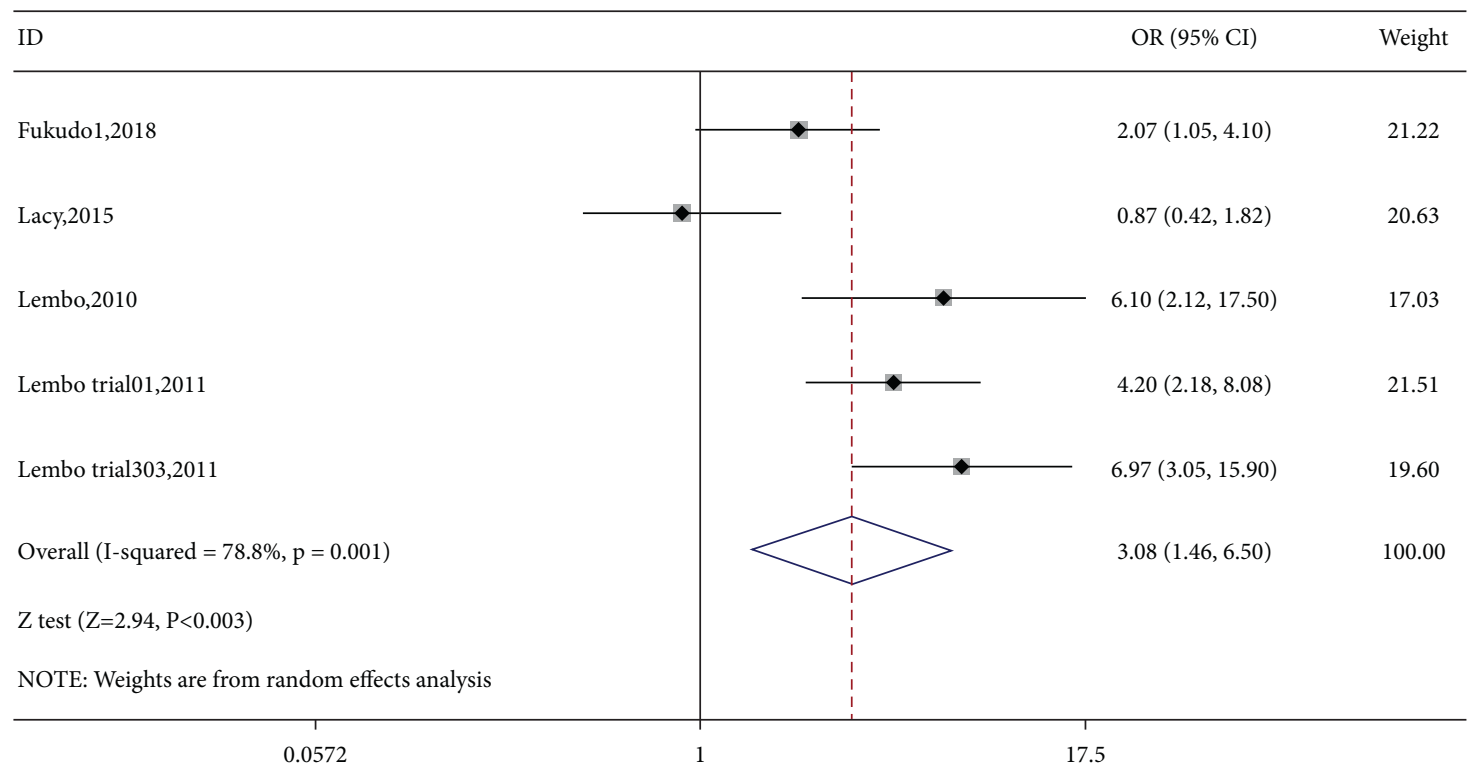

(d)

Figure 3: Continued. 


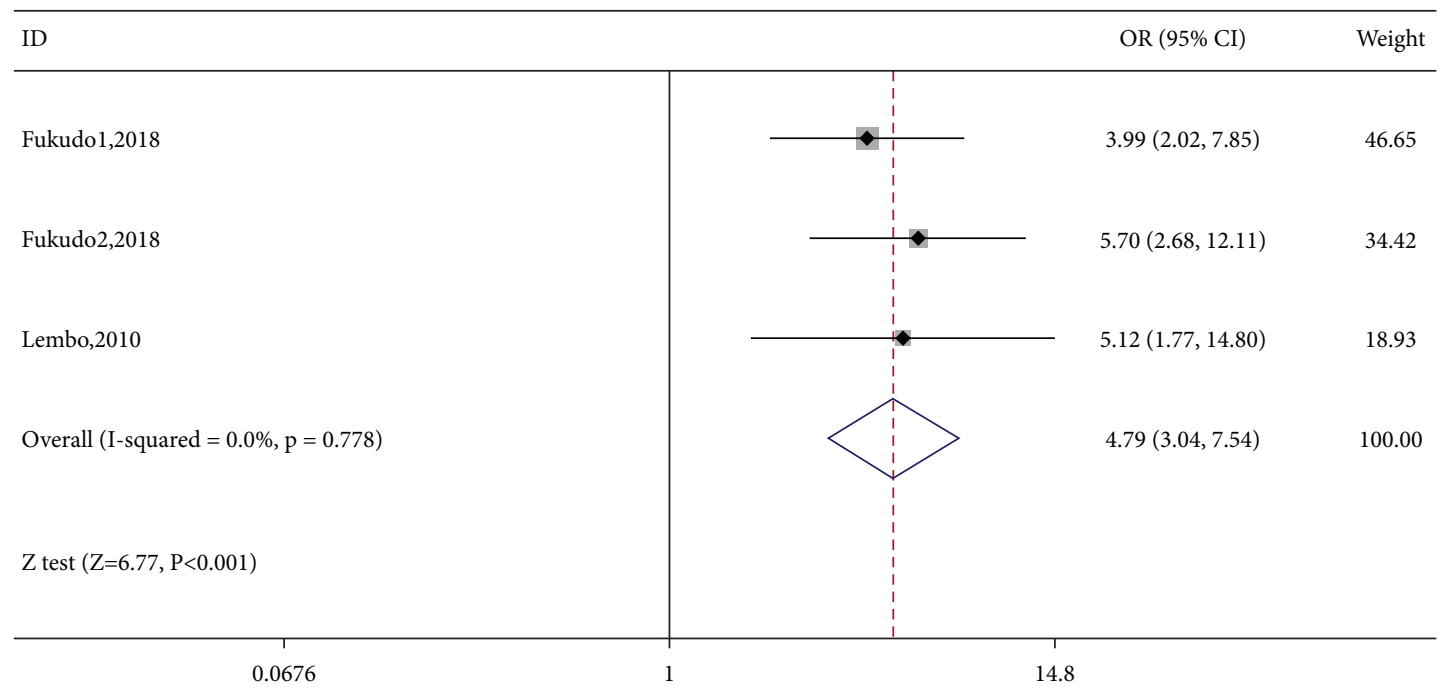

(e)

Figure 3: The forest plot of CSBM responder rate. (a) Linaclotide vs. placebo. (b) Extremely low dose of linaclotide vs. placebo. (c) Low dose of linaclotide vs. placebo. (d) Medium dose of linaclotide vs. placebo. (e) High dose of linaclotide vs. placebo.

TABLE 2: The summary of the secondary outcomes.

\begin{tabular}{|c|c|c|c|}
\hline Outcomes & $Z$ test & OR $(95 \% \mathrm{CI})$ & $P$ \\
\hline \multicolumn{4}{|l|}{ SBM responder rate } \\
\hline Linaclotide vs. placebo & 6.12 & $2.41(1.82,3.20)$ & $<0.001$ \\
\hline Low-dose group vs. medium-dose group & 1.42 & $0.75(0.50,1.12)$ & 0.156 \\
\hline \multicolumn{4}{|l|}{ Responder rate of the global assessment of relief } \\
\hline Linaclotide vs. placebo & 5.87 & $3.45(2.28,5.22)$ & $<0.001$ \\
\hline Low-dose group vs. medium-dose group & 0.49 & $0.95(0.77,1.17)$ & 0.626 \\
\hline \multicolumn{4}{|c|}{ Responder rate of abdominal bowel habits improvements } \\
\hline Linaclotide vs. placebo & 7.08 & $3.73(2.59,5.36)$ & $<0.001$ \\
\hline Low-dose group vs. medium-dose group & 1.20 & $1.29(0.85,1.97)$ & 0.230 \\
\hline \multicolumn{4}{|l|}{ Responder rate of abdominal symptoms relief } \\
\hline Linaclotide vs. placebo & 10.42 & $2.76(2.283 .34)$ & $<0.001$ \\
\hline Low-dose group vs. medium-dose group & 0.45 & $0.91(0.61,1.36)$ & 0.65 \\
\hline Outcomes & $Z$ test & $\mathrm{RR}(95 \% \mathrm{CI})$ & $P$ \\
\hline \multicolumn{4}{|c|}{ Adverse events between the linaclotide group and placebo } \\
\hline Any adverse events & 4.88 & $1.23(1.13,1.33)$ & $<0.001$ \\
\hline Gastrointestinal disorders & 3.31 & $2.03(1.34,3.09)$ & 0.001 \\
\hline Diarrhea & 9.12 & $3.10(2.43,3.95)$ & $<0.001$ \\
\hline Infections & 3.15 & $1.45(1.15,1.83)$ & 0.002 \\
\hline
\end{tabular}

OR, odds ratio; RR, risk ratio; $\mathrm{CI}$, confident interval.

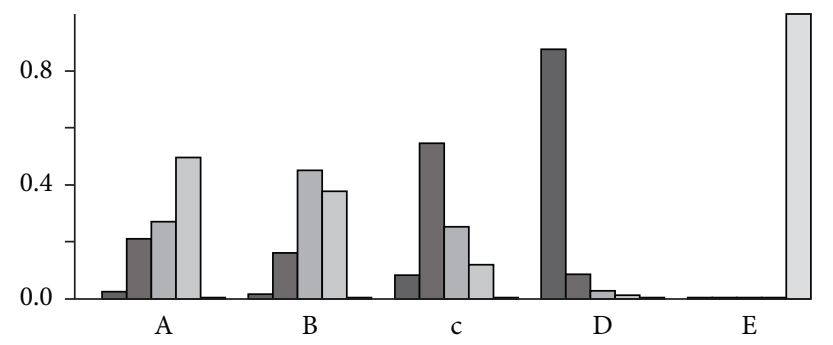

Rank 1

Rank 2

Rank 3

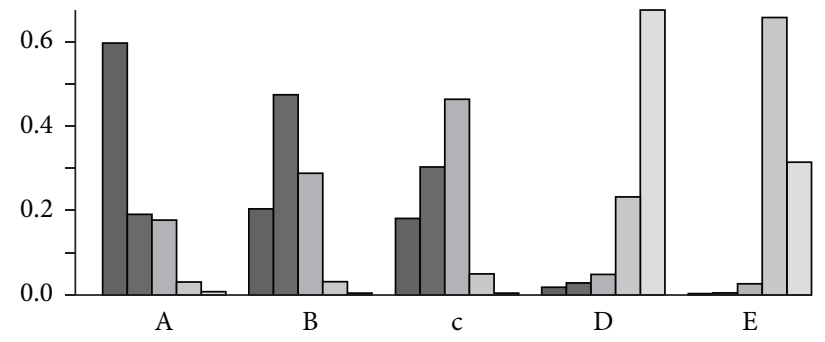

Rank 1

$\square$ Rank 4

Rank 2

Rank 3

(a)

(b)

FIGUre 4: Probability rank of CSBM responders (a) and any AEs (b) by Bayesian analysis. A, B, C, D, and E were the extremely low-dose group, low-dose group, medium-dose group, high-dose group, and placebo group, respectively. 
TABLE 3: Bayesian analysis of CSBM responder rate and any AEs following different dose of linaclotide.

\begin{tabular}{|l|c|c|c|c|}
\hline $\begin{array}{l}\text { Extremely low } \\
\text { dose group }\end{array}$ & $\begin{array}{c}\mathrm{RR}(95 \% \mathrm{Crl}) \\
1.07(0.81,1.48)\end{array}$ & $\begin{array}{c}\mathrm{RR}(95 \% \mathrm{Crl}) \\
1.09(0.78,1.51)\end{array}$ & $\begin{array}{c}\mathrm{RR}(95 \% \mathrm{Crl}) \\
1.49(0.94,2.5)\end{array}$ & $\begin{array}{c}\mathrm{RR}(95 \% \mathrm{Crl}) \\
1.34(1.05,1.96)\end{array}$ \\
\hline $\mathrm{OR}(95 \% \mathrm{Crl})$ & Low dose group & $\mathrm{RR}(95 \% \mathrm{Crl})$ & $\mathrm{RR}(95 \% \mathrm{Crl})$ & $\mathrm{RR}(95 \% \mathrm{Crl})$ \\
$0.97(0.66,1.43)$ & $1.03(0.79,1.24)$ & $1.39(0.92,2.2)$ & $1.26(1.06,1.62)$ \\
\hline $\mathrm{OR}(95 \% \mathrm{Crl})$ & $\mathrm{OR}(95 \% \mathrm{Crl})$ & $\begin{array}{c}\text { Medium dose } \\
\text { group }\end{array}$ & $\begin{array}{c}\mathrm{RR}(95 \% \mathrm{Crl}) \\
1.36(0.89,2.23)\end{array}$ & $\mathrm{RR}(95 \% \mathrm{Crl})$ \\
$0.87(0.57,1.33)$ & $0.89(0.66,1.22)$ & $\mathrm{O}(1.03,1.67)$ \\
\hline $\mathrm{OR}(95 \% \mathrm{Crl})$ & $\mathrm{OR}(95 \% \mathrm{Crl})$ & $\mathrm{OR}(95 \% \mathrm{Crl})$ & High dose & $\mathrm{RR}(95 \% \mathrm{Crl})$ \\
$0.65(0.39,1.06)$ & $0.67(0.42,1.05)$ & $0.74(0.47,1.19)$ & group & $0.91(0.60,1.38)$ \\
\hline $\mathrm{OR}(95 \% \mathrm{Crl})$ & $\mathrm{OR}(95 \% \mathrm{Crl})$ & $\mathrm{OR}(95 \% \mathrm{Crl})$ & $\mathrm{OR}(95 \% \mathrm{Crl})$ & placebo \\
$3.2(2.12,4.89)$ & $3.28(2.4,4.6)$ & $3.66(2.61,5.25)$ & $4.94(3.22,7.79)$ & \\
\hline
\end{tabular}

CSBM responder rate;

any $\mathrm{AE}$

95\% Crl: 95\% credible interval; RR: risk ratio; OR: odds ratio; CSBM: completely spontaneous bowl movement; any AEs: any adverse events

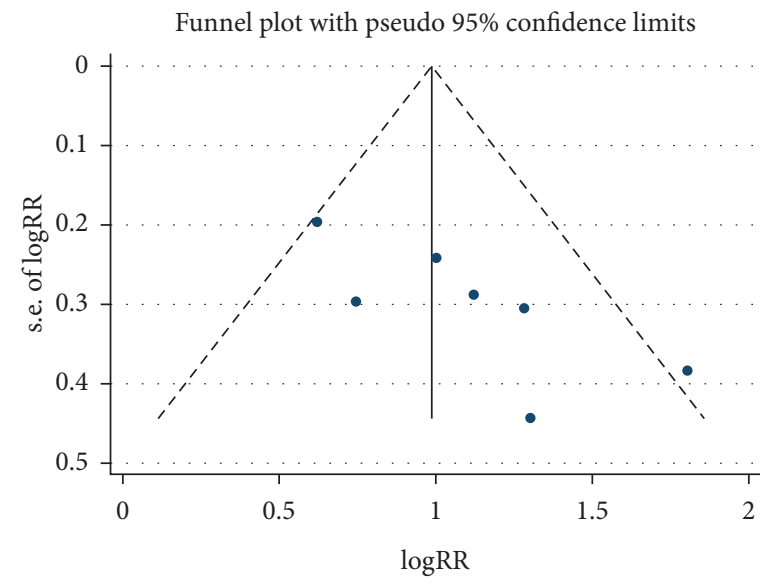

(a)

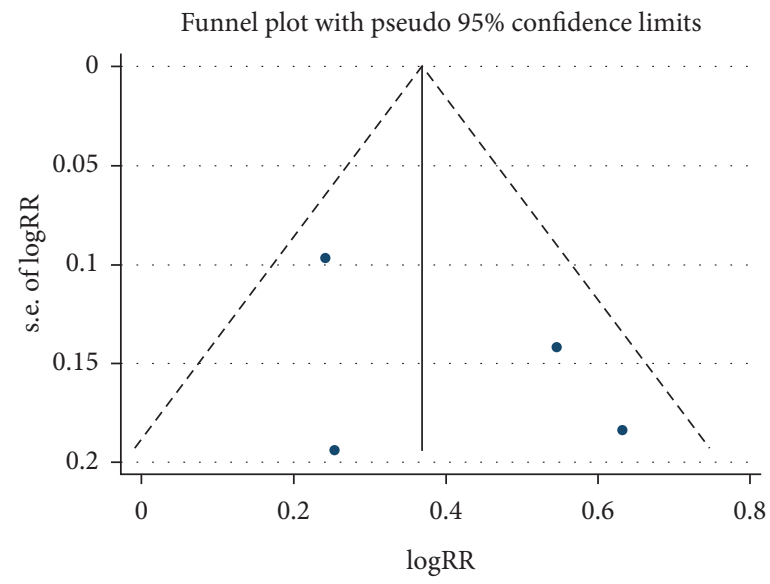

(b)

Funnel plot with pseudo 95\% confidence limits

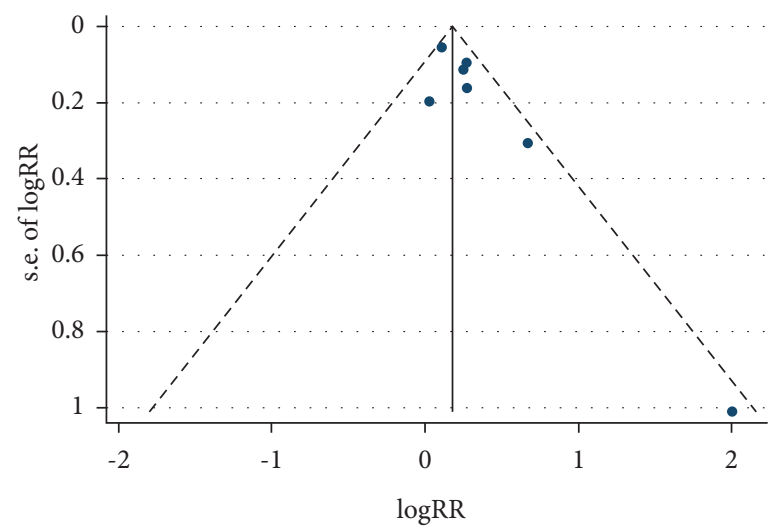

(c)

FIgURE 5: The funnel plot of outcomes between the linaclotide groups and placebo. (a) CSBM responder. (b) SBM responder. (c) Any adverse events.

respectively). But we failed to demonstrate that patients with high dose of linaclotide obtain more CSBM responders by a direct pairwise efficacy comparison between the different doses of linaclotide.

In addition, more patients administered with oral linaclotide presented the global assessment of relief (OR:
3.45), abdominal bowel habits improvement (OR: 3.73), and abdominal symptoms relief (OR: 2.76), compared with those administered the placebo. For the low dose and medium dose of linaclotide groups, the global assessment of relief responder rate was $45.70 \%$ and $46.79 \%$, respectively, indicating that a higher dose of linaclotide provided no 
significant improvement in the global assessment of relief. The responder rate of abdominal bowel habits improvement and abdominal symptoms relief was $32.29 \%$ and $27.27 \%$, and $56.83 \%$ and $58.76 \%$ between the low and medium dose of linaclotide groups, respectively, and showed no statistical significance. These results can be explained by the effect of linaclotide in reducing visceral sensitivity, as proven using rodent models of visceral pain [34]. These benefits appear to persist along with longer-term administration [21].

The most common adverse events of linaclotide are diarrhea and gastrointestinal disorders. Here, we reported the incidence of any AEs, gastrointestinal disorders, diarrhea, and infections in patients with linaclotide were all higher than those with the placebo. Most AEs were mild or moderate. Only one eligible study reported on diarrhea that resulted from the discontinuation of $0,2.4 \%$, and $3.2 \%$ of patients in the placebo, linaclotide $72 \mu \mathrm{g}$ group, and linaclotide $145 \mu \mathrm{g}$ group, respectively [29]. We analyze the incidence of any AEs in patients with different doses of linaclotide by the Bayesian model and found extremely low dose holds the highest incidence (RR: 1.34; 95\% CrI: $1.05-1.96$, probability rank $=0.59$ ) by indirect comparison with other different doses of linaclotide. The high dose ranked the lowest (RR: 0.91 ; $95 \%$ CrI: $0.60-1.38$, probability rank $=0.01$ ). However, direct comparison between different doses of linaclotide showed no significant difference in increasing the incidence of any AEs, which may indicate no positive correlation between dosage and any AEs. A previous study investigated the dose of linaclotide on healthy human volunteers and found that linaclotide was welltolerated at oral doses of up to $3000 \mu \mathrm{g}$ with no detectable change in serum levels [35]. However, one study showed that diarrhea was the only dose-dependent adverse event and was usually mild or moderate [33] which is needed to explore furtherly.

There are some limitations to this study. First, the number of eligible studies was small. Second, most studies were conducted in the United States or Japan. There was a lack of data from China and European countries. The dose of linaclotide may be different for patients of different genetic backgrounds. Third, the dose of linaclotide for different dose groups was not a single value but was a category. Fourth, efficacy parameters, such as the change in mean CSBM/SBM frequency, change in mean stool form score, and improvement of health-related quality of life, were lacking due to the unavailability of relevant data, which may change the conclusion. Finally, the definition of CC used in our study is broad and included certain secondary factors, such as medications. Therefore, there may be some discrepancies in the efficacy of different linaclotide doses between primary CC and secondary CC.

In conclusion, high dose of linaclotide could be more effective and safer for CC patients which need more trials to confirm in the future.

\section{Data Availability}

The data used to support the findings of this study are available in the published articles in PubMed, the
Cochrane Library, and the Embase and are included within the article.

\section{Conflicts of Interest}

The authors declare that they have no conflicts of interest.

\section{Supplementary Materials}

Figure S1: the level of evidence of the CSBM responder rate; any $\mathrm{AE}$ 95\% Crl, 95\% credible interval; RR, risk ratio; OR, odds ratio; CSBM, completely spontaneous bowl movement; any AEs, any adverse events. (Supplementary Materials)

\section{References}

[1] F. Mearin, B. E. Lacy, L. Chang, W. D. Chey, A. J. Lembo, and M. Simren, "Bowel disorders," Gastroenterology, vol. 150, pp. 1393-1407, 2016.

[2] J. Tack, M. Camilleri, D. Dubois, L. Vandeplassche, A. Joseph, and R. Kerstens, "Association between health-related quality of life and symptoms in patients with chronic constipation: an integrated analysis of three phase 3 trials of prucalopride," Neuro-Gastroenterology and Motility, vol. 27, no. 3, pp. 397-405, 2015.

[3] A. Wald, C. Scarpignato, and M. A. Kamm, "The burden of chronic constipation on quality of life: results of a multinational survey," Alimentary Pharmacology \& Therapeutics, vol. 26, pp. 227-236, 2007.

[4] C. V. Almario, M. L. Ballal, W. D. Chey, C. Nordstrom, D. Khanna, and B. M. R. Spiegel, "Burden of gastrointestinal symptoms in the United States: results of a nationally representative survey of over 71,000 Americans," American Journal of Gastroenterology, vol. 113, no. 11, pp. 1701-1710, 2018.

[5] P. D. R. Higgins and J. F. Johanson, "Epidemiology of constipation in north America: a systematic review," American Journal of Gastroenterology, vol. 99, no. 4, pp. 750-759, 2004.

[6] T. Sommers, S. Mitsuhashi, P. Singh et al., "Prevalence of chronic constipation and chronic diarrhea in diabetic individuals in the United States," American Journal of Gastroenterology, vol. 114, no. 1, pp. 135-142, 2019.

[7] D. A. Drossman, Z. Li, E. Andruzzi et al., "US householder survey of functional gastrointestinal disorders. prevalence, sociodemography, and health impact," Digestive Diseases and Sciences, vol. 38, pp. 1569-1580, 1993.

[8] N. D. Shah, D. K. Chitkara, G. R. Locke, P. D. Meek, and N. J. Talley, "Ambulatory care for constipation in the United States, 1993-2004," American Journal of Gastroenterology, vol. 103, no. 7, pp. 1746-1753, 2008.

[9] L. Neri, G. Basilisco, E. Corazziari, V. Stanghellini, G. Bassotti, and M. Bellini, "Constipation severity is associated with productivity losses and healthcare utilization in patients with chronic constipation," United European Gastroenterology Journal, vol. 2, no. 2, pp. 138-147, 2014.

[10] M. Bellini, P. Usai-Satta, A. Bove et al., "Chronic constipation diagnosis and treatment evaluation: the "CHRO.CO.DI.T.E." study," BMC Gastroenterology, vol. 17, no. 1, p. 11, 2017.

[11] A. E. Bharucha, G. R. Locke III, and J. H. Pemberton, "American gastro-enterological association technical review on constipation," Gastroenterology, vol. 14, no. 1, pp. 218-238, 2013. 
[12] N. Baffy, A. E. Foxx-Orenstein, L. A. Harris, and S. Sterler, "Intractable constipation in the elderly," Current Treatment Options in Gastroenterology, vol. 15, no. 3, pp. 363-381, 2017.

[13] J. F. Johanson and J. Kralstein, "Chronic constipation: a survey of the patient perspective," Alimentary Pharmacology \& Therapeutics, vol. 25, no. 5, pp. 599-608, 2007.

[14] A. D. Farmer, J. K. Ruffle, and A. R. Hobson, "Linaclotide increases cecal $\mathrm{pH}$, accelerates colonic transit, and increases colonic motility in irritable bowel syndrome with constipation," Neuro-Gastroenterology and Motility, vol. 31, no. 2, Article ID e13492, 2019.

[15] P. Luthra, M. Camilleri, N. E. Burr, E. M. M. Quigley, C. J. Black, and A. C. Ford, "Efficacy of drugs in chronic idiopathic constipation: a systematic review and network meta-analysis," The Lancet Gastroenterology \& Hepatology, vol. 4, no. 11, pp. 831-844, 2019.

[16] A. D. Nelson, M. Camilleri, S. Chirapongsathorn et al., "Comparison of efficacy of pharmacological treatments for chronic idiopathic constipation: a systematic review and network meta-analysis," Gut, vol. 66, no. 9, pp. 1611-1622, 2017.

[17] J. W. Nee, J. M. Johnston, E. P. Shea et al., "Safety and tolerability of linaclotide for the treatment of chronic idiopathic constipation and irritable bowel syndrome with constipation: pooled phase 3 analysis," Expert Review of Gastroenterology \& Hepatology, vol. 13, no. 4, pp. 397-406, 2019.

[18] A. J. Lembo, H. A. Schneier, S. J. Shiff, C. B. Kurtz, J. E. MacDougall, and X. D. Jia, "Two randomized trials of linaclotide for chronic constipation," New England Journal of Medicine, vol. 365, pp. 527-536, 2011.

[19] S. Rao, A. J. Lembo, S. J. Shiff, B. J. Lavins, M. G. Currie, and X. D. Jia, "A 12-week, randomized, controlled trial with a 4week randomized withdrawal period to evaluate the efficacy and safety of linaclotide in irritable bowel syndrome with constipation," American Journal of Gastroenterology, vol. 107, no. 11, pp. 1714-1724, 2012.

[20] E. M. Quigley, J. Tack, W. D. Chey et al., "Randomised clinical trials: linaclotide phase 3 studies in IBS-C-a prespecified further analysis based on European medicines agency-specified endpoints," Alimentary Pharmacology \& Therapeutics, vol. 37, no. 1, pp. 49-61, 2013.

[21] W. D. Chey, A. J. Lembo, B. J. Lavins, S. J. Shiff, C. B. Kurtz, and M. G. Currie, "Linaclotide for irritable bowel syndrome with constipation: a 26-week, randomized, double-blind, placebo-controlled trial to evaluate efficacy and safety," American Journal of Gastroenterology, vol. 107, no. 11, pp. 1702-1712, 2012.

[22] S. Fukudo, A. Nakajima, Y. Fujiyama et al., "Determining an optimal dose of linaclotide for use in Japanese patients with irritable bowel syndrome with constipation: a phase II randomized, double-blind, placebo-controlled study," NeuroGastroenterology and Motility, vol. 30, no. 5, Article ID e13275, 2018.

[23] G. Salanti, A. E. Ades, and J. P. Ioannidis, "Graphical methods and numerical summaries for presenting results from multiple-treatment meta-analysis: an overview and tutorial," Journal of Clinical Epidemiology, vol. 64, no. 2, pp. 163-171, 2011.

[24] G. Lu and A. E. Ades, "Combination of direct and indirect evidence in mixed treatment comparisons," Statistics in Medicine, vol. 23, no. 20, pp. 3105-3124, 2004.

[25] A. J. Lembo, C. B. Kurtz, J. E. Macdougall et al., "Efficacy of linaclotide for patients with chronic constipation," Gastroenterology, vol. 138, no. 3, pp. 886-895 e1, 2010.
[26] B. E. Lacy, R. Schey, S. J. Shiff, B. J. Lavins, S. M. Fox, and X. D. Jia, "Linaclotide in chronic idiopathic constipation patients with moderate to severe abdominal bloating: a randomized, controlled trial," PLoS One, vol. 10, no. 7, Article ID e0134349, 2015.

[27] S. Fukudo, H. Miwa, A. Nakajima et al., "Dose-finding study of linaclotide in Japanese patients with chronic constipation: a phase II randomized, double-blind, and placebo-controlled study," Neuro-Gastroenterology and Motility, vol. 30, no. 12, Article ID e13442, 2018.

[28] S. Fukudo, H. Miwa, A. Nakajima et al., "High-dose linaclotide is effective and safe in patients with chronic constipation: a phase III randomized, double-blind, placebocontrolled study with a long-term open-label extension study in Japan," Neuro-Gastroenterology and Motility, vol. 31, no. 1, Article ID e13487, 2019.

[29] P. Schoenfeld, B. E. Lacy, W. D. Chey, A. J. Lembo, C. B. Kurtz, and D. S. Reasner, "Low-dose linaclotide (72 mug) for chronic idiopathic constipation: a 12-week, randomized, double-blind, placebo-controlled trial," American Journal of Gastroenterology, vol. 113, no. 1, pp. 105-114, 2018.

[30] D. M. Brenner, C. E. Argoff, S. M. Fox et al., "Efficacy and safety of linaclotide for opioid-induced constipation in patients with chronic noncancer pain syndromes from a phase 2 randomized study," Pain, vol. 161, no. 5, pp. 1027-1036, 2020.

[31] E. D. Shah, H. M. Kim, and P. Schoenfeld, "Efficacy and tolerability of guanylate cyclase-C agonists for irritable bowel syndrome with constipation and chronic idiopathic constipation: a systematic review and meta-analysis," American Journal of Gastroenterology, vol. 113, pp. 329-338, 2018.

[32] J. M. Johnston, C. B. Kurtz, D. A. Drossman et al., "Pilot study on the effect of linaclotide in patients with chronic constipation," American Journal of Gastroenterology, vol. 104, no. 1, pp. 125-132, 2009.

[33] J. M. Johnston, C. B. Kurtz, J. E. Macdougall et al., "Linaclotide improves abdominal pain and bowel habits in a phase IIb study of patients with irritable bowel syndrome with constipation," Gastroenterology, vol. 139, no. 6, pp. 1877-1886 e2, 2010.

[34] H. Eutamene, S. Bradesi, M. Larauche, V. Theodorou, C. Beaufrand, and G. Ohning, "Guanylate cyclase C-mediated antinociceptive effects of linaclotide in rodent models of visceral pain," Neuro-Gastroenterology and Motility, vol. 22, no. 3, pp. 312-e84, 2010.

[35] C. B. Kurtz, D. Fitch, and R. W. Busby, "Effects of multidose administration of MD-1100 on safety, tolerability, exposure, and phamacoldynamics in healthy subjects," Gastroenterology, vol. 130, p. A26, 2006. 